\title{
Oncolytic poliovirus therapy and immunization with poliovirus-infected cell lysate induces potent antitumor immunity against neuroblastoma in vivo
}

\author{
HIDEMI TOYODA, ECKARD WIMMER and JERONIMO CELLO \\ Department of Molecular Genetics and Microbiology, Stony Brook University, Stony Brook, NY 11790, USA
}

Received July 19, 2010; Accepted September 3, 2010

DOI: 10.3892/ijo_00000826

\begin{abstract}
In a previous study, we demonstrated that neuroblastoma subcutaneously implanted in immuno-competent mice is eliminated by intratumoral administration of neuroattenuated poliovirus (PV). Our results also suggested that the in vivo destruction of neuroblastoma cells by virotherapy lead to a robust antitumor immune response. In this work, splenocytes harvested from neuroblastoma-bearing animals treated with neuroattenuated PV exhibited significantly higher lytic activity against tumor target cells than did those from splenocytes derived from control mice. In vitro T-cell depletion experiments indicated that $\mathrm{CD} 8^{+} \mathrm{T}$ cells were essential for the cytotoxic antitumor activity of splenocytes. Moreover, adoptive transfer of splenocytes obtained from mice cured of neuroblastoma by PV virotherapy markedly delayed the tumor growth of previously established neuroblastomas in recipient naïve mice. These results confirmed that treatment with a neuroattenuated oncolytic PV strain induces antitumor immunity against neuroblastoma that is mainly mediated by cytotoxic $\mathrm{CD} 8^{+} \mathrm{T}$ cells. Immunocompetent mice, on the other hand, were immunized with PV-infected neuroblastoma cell lysate prior intravenous challenge with neuroblastoma cells. As a control, mice were vaccinated with either non-infected neuroblastoma cell lysate alone or mixed with PV, or with PBS prior tumor cell injection. Results showed that survival is significantly prolonged only in mice immunized with PV-infected tumor lysate. This finding clearly suggested that in vitro poliovirus infection of neuroblastoma cells turns these cells into a potent tumor immunogen. Further studies in oncolytic treatment of neuroblastoma using attenuated PV alone or in combination with immunotherapy with PV oncolysate should improve the probability for successful translation in the clinic.
\end{abstract}

Correspondence to: Dr Jeronimo Cello, Department of Molecular Genetics and Microbiology, School of Medicine, Stony Brook University, Stony Brook, NY 11794-5222, USA

E-mail: jcello@ms.cc.sunysb.edu

Key words: oncolytic poliovirus, neuroblastoma, immunity, viral oncolysate

\section{Introduction}

Neuroblastoma, a malignant embryonal tumor of the neural crest cells, is one of the most common solid extracranial tumors of early childhood (1). In contrast to many other pediatric malignancies, progress in the treatment of neuroblastoma (especially for advanced-stage tumors) has been relatively modest. Although a fraction of the patients are cured with current treatments, approximately $40 \%$ will die of this disease $(2,3)$. Moreover, as neuroblastoma is a disease that most often strikes young children, treating patients with aggressive therapy is a concern because of the potential for long-term health implications (from heart disease to second malignancies). Therefore new neuroblastoma treatments employing novel mechanisms of action are needed. Such new treatments may be based on human non-pathogenic and pathogenic viruses (4-6). An oncolytic virus is a replicating agent that has either been naturally selected or engineered to single out and destroy tumor cells (4-6).

Poliovirus has recently been added to the list of viruses that hold promise as possible agents in tumor therapy (7-9). In our previous study, we constructed a highly neuroattenuated poliovirus that may be suitable for the treatment of neuroblastoma in children (10). Moreover, we developed fully immunocompetent mice (CD155 $\mathrm{tg} \mathrm{A} / \mathrm{J}$ mice) that express the human poliovirus receptor (CD155) and accept mouse neuroblastoma cells (Neuro-2 $\mathrm{a}^{\mathrm{CD} 155}$ ) expressing CD155 (10). Using this animal model, we demonstrated that subcutaneous tumors of Neuro- $2 \mathrm{a}^{\mathrm{CD} 155}$ cells were eliminated by intratumoral administrations of the neuroattenuated PV in polio-immunized mice (10). Remarkably, the tumor-bearing mice, which were cured through treatment with neuroattenuated poliovirus derivative $\mathrm{A}_{133}$ Gmono-crePV, resisted attempts to re-establish neuroblastoma with Neuro- $2 \mathrm{a}^{\mathrm{CD} 155}$ cells (10). Based on these results, we hypothesized that destruction of tumor cells by neuroattenuated PV can increment the release of tumor antigens which may induce a more efficient antigen presentation and the development of a robust antitumor immunity (10).

In line with our hypothesis, previous investigations in mice and humans have also shown that treatment with oncolytic viruses can result in the enhancement of antitumor immune response (11-17). Moreover, different stimuli can promote an immunogenic cell death of tumor cells. Immunogenic cell death implies that dying tumor cells release several cellular 
signals that will facilitate immune recognition and elimination of tumor cells $(18,19)$. Noteworthy, it has been speculated that virus infection of tumor cells may induce an immunogenic cell death (20).

In this study, we have characterized the antitumor immune response evoked by the treatment of subcutaneous neuroblastoma by an attenuated poliovirus strain. Our results indicate that oncolytic poliovirus therapy induces antitumor immunity against neuroblastoma that is mediated by cytotoxic $\mathrm{CD} 8^{+}$ $\mathrm{T}$ cells. In addition, we show that immunization of CD155 $\operatorname{tg} \mathrm{A} / \mathrm{J}$ mice with $\mathrm{PV}$-infected neuroblastoma lysate provides protection against neuroblastoma development. These findings should be considered when designing therapies against poorly immunogenic human tumors.

\section{Materials and methods}

Cells and viruses. The neurovirulent poliovirus type 1 (Mahoney) [PV1(M)] is the strain being used routinely in the laboratory (21). A novel attenuated oncolytic poliovirus, $\mathrm{A}_{133} \mathrm{Gmono}-$ crePV, which is a derivative of mono-crePV, was described previously (10). The mouse neuroblastoma cell line stably expressing CD155 $\alpha$ (Neuro-2 $\mathrm{a}^{\mathrm{CD} 155}$ ) has been described (10) (22). Neuro-2a $\mathrm{a}^{\mathrm{CD} 155}$ cells, which are highly susceptible to poliovirus infection, were maintained in Dulbecco's modified Eagle's medium containing $1 \%$ penicillin/streptomycin and $10 \%$ fetal bovine serum. The neuroblastoma cells Neuro-2a were purchased from American Type Culture Collection (ATCC) and the cells were authenticated by isoenzyme analysis.

Cytotoxicity assays. CD155 tgA/J mice were immunized by intraperitoneal injection of mono-crePV $\left(1 \times 10^{8} \mathrm{pfu}\right)$ three times with intervals of one week. On the day 21 after the last immunization, Neuro- $2 \mathrm{a}^{\mathrm{CD} 155}$ cells $\left(1 \times 10^{7}\right)$ were subcutaneously implanted in the right flank of each CD155 tgA/ J-immunized mouse. When the subcutaneous tumor volumes were approximately $170 \mathrm{~mm}^{3}$ (7-12 days after implantation), mice were inoculated intratumorally with $\mathrm{A}_{133}$ Gmono-crePV. Tumor growth was determined by measuring the tumor volume (length $\mathrm{x}$ width $\mathrm{x}$ height) every day. Spleens were removed from mice that survived without signs of subcutaneous tumor for 10 months after oncolytic therapy. As the control mice, subcutaneous Neuro-2a $\mathrm{a}^{\mathrm{CD} 155}$ tumors were established in the $C D 155 \mathrm{tgA} / \mathrm{J}$ mice immunized with mono-crePV. The control mice were inoculated intratumorally with PBS and sacrificed after the tumor had reached a volume of $\sim 500 \mathrm{~mm}^{3}$ and spleens were used as a control. Tumor-specific cytotoxicity of splenocytes was determined by lactate dehydrogenase-release assays as described in detail elsewhere (23). Briefly, splenocytes prepared by centrifugation over a Ficoll-Hypaque gradient were used as effector cells and Neuro-2 $\mathrm{a}^{\mathrm{CD} 155}$ cells or Neuro-2a cells were used as target cells. The effector cells were not stimulated in vitro with target cells prior to the cytotoxicity assay. Target cells/well $\left(1 \times 10^{4}\right)$ on a 96 -well flat bottom plate were mixed with $5 \times 10^{5}$ effector cells in $200 \mu 1$ of serum-free medium and incubated for $12 \mathrm{~h}$ at $37^{\circ} \mathrm{C}$ in $5 \% \mathrm{CO}_{2}$. The cytotoxicity of effector cells against target cells was determined by using Cytotoxicity detection kit (Roche) according to the manufacturer's manual. The percentage of specific lysis was calculated as [(experimental - effector spontaneous - target spontaneous)/ (target maximum - target spontaneous)] x 100. In order to characterize the effector cells, same experiments were performed after immunomagnetic depletion of $\mathrm{CD}^{+}, \mathrm{CD}^{+}$ or NK cells. For this purpose, splenocytes were incubated for 30 min with biotinylated antibodies against mouse CD8 $\alpha$ (Ly3.4), CD4 (L3T4) or NK1.1 (PK136) (all from BD Pharmingen). Cells were rinsed with cold PBS with $1 \%$ BSA and incubated with streptavidin microbeads (BD ${ }^{\mathrm{TM}}$ IMAG, BD Pharmingen). Positive cells were removed with a magnet (IMagnet, BD Pharmingen). Each determination was performed by triplicate.

Animal studies. The transgenic mice that express human CD155 under its original promoter (ICR-CD155/Tg21) were kindly provided by Dr A. Nomoto (24). The CD155 tg mice were kept in the homozygous state. A/J mice, which express the major histocompatibility complex (MHC) haplotype H-2a, were purchased from the Jackson Laboratories. A/J mice carrying CD155 gene were obtained by outcrossing $\mathrm{A} / \mathrm{J}$ mice with $C D 155$ tg mice and called $C D 155 \mathrm{tg} \mathrm{A} / \mathrm{J}$ mice (10). The CD155 $\operatorname{tg} \mathrm{A} / \mathrm{J}$ mice show paralysis after PV inoculation and accept Neuro-2a cells and Neuro- $2 \mathrm{a}^{\mathrm{CD} 155}$ cells for the formation of lethal neuroblastoma (10). Mice were at least six weeks of age before use. All procedures involving experimental mice were conducted according to protocols approved by the institutional committees on animal welfare.

Adaptive transfer of splenocytes. Neuro- $2 \mathrm{a}^{\mathrm{CD} 155}$ cells $\left(1 \times 10^{7}\right)$ were subcutaneously implanted in the right flank of $\mathrm{A} / \mathrm{J}$ mice (2A, I). Approximately 10 days after tumor cell inoculation, when the local tumor became palpable in the mice, the animals were received 4 intratumoral injections of $\mathrm{A}_{133}$ Gmono-crePV (2A, II). The resultant local tumor growth was monitored by measuring tumor diameters and mice were followed for up to 2 months after treatment. The animals that survived without signs of tumor relapse for 2 months were used as cured A/J mice and their splenocytes were used for adaptive transfer. Splenocytes of naïve $\mathrm{A} / \mathrm{J}$ mice were used as control. Prior to harvesting splenocytes, Neuro- $2 \mathrm{a}^{\mathrm{CD} 155}$ cells $\left(1 \times 10^{7}\right)$ were subcutaneously implanted in the right flank of naïve $\mathrm{A} / \mathrm{J}$ mice (2A, IV). When the subcutaneous tumor volumes were approximately $170 \mathrm{~mm}^{3}$ (7-12 days after implantation), splenocytes were harvested from cured $\mathrm{A} / \mathrm{J}$ mice and control $\mathrm{A} / \mathrm{J}$ mice (2A, III). The harvested splenocytes were washed and resuspended in PBS, and then injected intravenously into the tail veins of tumor-bearing mice $\left(2 \times 10^{7}\right.$ cells in $100 \mu 1$ per mouse) (2A, V). Tumor volume was measured every day after animals received the adaptive immunotherapy using the formula: length $\mathrm{x}$ width $\mathrm{x}$ height.

Animal vaccination with cell lysates and tumor challenge. Neuro- $2 \mathrm{a}^{\mathrm{CD} 155}$ cell monolayers $\left(1 \times 10^{7}\right.$ cells $)$ were incubated with PV1(M) at multiplicity of infection (MOI) of 50 or with $\mathrm{PBS}$ at $37^{\circ} \mathrm{C}$. After $6 \mathrm{~h}$, the cells were harvested and subjected to three consecutive freeze-thaw cycles followed by 10 strokes of a Dounce homogenizer for the preparation of non-infected and PV-infected Neuro- $2 \mathrm{a}^{\mathrm{CD} 155}$ lysates. The poliovirus titer in the PV-infected Neuro- $2 \mathrm{a}^{\mathrm{CD} 155}$ lysate was 
$5 \times 10^{8} \mathrm{pfu} / \mathrm{ml}$. For the tumor rejection assays, CD155 $\operatorname{tgA} / \mathrm{J}$ mice were first immunized with mono-crePV $\left(1 \times 10^{8} \mathrm{pfu}\right)$ intraperitoneally thrice at 1 -week intervals $(3 \mathrm{~A}, \mathrm{I})$. High titers of neutralizing antibodies against poliovirus were detectable in all mice at day 21 post-immunization (data not shown). Then, polio-immunized $C D 155 \mathrm{tg} \mathrm{A} / \mathrm{J}$ mice were injected intraperitoneally with $\mathrm{PV}$-infected Neuro-2 $\mathrm{a}^{\mathrm{CD} 155}$ lysate, or non-infected Neuro- $2 \mathrm{a}^{\mathrm{CD} 155}$ lysate, or a mixture of noninfected Neuro-2 $\mathrm{a}^{\mathrm{CD} 155}$ lysate plus poliovirus (poliovirus titer in the mixture was $5 \times 10^{8} \mathrm{pfu} / \mathrm{ml}$ ) or PBS thrice at 1 -week interval (3A, II). All mice were challenged intravenously with $2 \times 10^{6}$ Neuro- $2 \mathrm{a}^{\mathrm{CD} 155}$ cells 21 days after last injection with lysates or PBS (3A, III). At the first sign of any distress mice were sacrificed. Survival, defined as the time to either sacrifice or death, were monitored daily and body weight was measured thrice a week.

Statistical analysis. Life expectancies between groups of mice were estimated by the Kaplan-Meier method. Statistical significance in different treatment groups was compared using the log-rank test. Statistical significance was determined at the level of $\mathrm{p}<0.05$.

\section{Results}

Cytotoxicity of splenocyte from immune-competent mice treated with intratumoral injections of $A_{133}$ Gmono-crePV. In a previous work, we showed that neuroblastoma-bearing mice, which were cured through treatment with novel neuroattenuated poliovirus derivative $\left(\mathrm{A}_{133} \mathrm{Gmono}-\mathrm{cre} \mathrm{PV}\right)$, resisted attempts to re-establish neuroblastoma tumors by reseeding with Neuro- $2 \mathrm{a}^{\mathrm{CD} 155}(10)$. This prompted us to suggest that the destruction of Neuro- $2 \mathrm{a}^{\mathrm{CD} 155}$ tumors in CD155 $\operatorname{tg} \mathrm{A} / \mathrm{J}$ mice by intratumoral injection of attenuated poliovirus derivates induce anti-neuroblastoma immunity (10).

Based on these results, we proceeded to characterize the antitumor immune response evoked by the treatment of subcutaneous neuroblastoma by $\mathrm{A}_{133}$ Gmono-crePV. To evaluate the cellular antitumor immunity induced by oncolytic PV therapy, we quantified the cytolytic antitumor activity of splenocytes collected from those $C D 155 \mathrm{tg} \mathrm{A} / \mathrm{J}$ mice that were originally implanted with neuroblastoma but subsequently cured by four intratumoral inoculations of $\mathrm{A}_{133}$ Gmonocre $\mathrm{PV}$. Mock-treated mice received equivalent intratumoral injections of PBS. Splenocytes isolated from mice cured from neuroblastoma exhibited higher lytic activity against both target cells tested, Neuro- $2 \mathrm{a}^{\mathrm{CD} 155}$ and Neuro-2a, than did those from splenocytes derived from control mice (Fig. 1A). These results strongly supported our hypothesis that treatment with a neuroattenuated oncolytic PV strain induces antitumor immunity against neuroblastoma.

To determine which cell subpopulations are responsible for the cell-mediated antitumor immune responses, splenocytes from the cured mice were depleted in vitro of $\mathrm{NK}$, $\mathrm{CD}^{+}{ }^{+}$or $\mathrm{CD}^{+}$cells respectively, prior to cytotoxic assay. As shown in Fig. 1B, incubation of splenocytes with neutralizing antibody NK1.1 or anti-CD4 had little or no effect on their ability to kill Neuro- $2 \mathrm{a}^{\mathrm{CD} 155}$ cells. In contrast, depletion of $\mathrm{CD}^{+}$cells abrogated the cytolytic activity of splenocytes from cured mice by $\sim 70 \%$ compared to non-depleted splenocytes

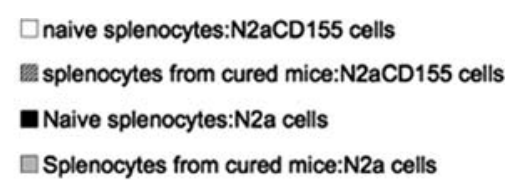

A

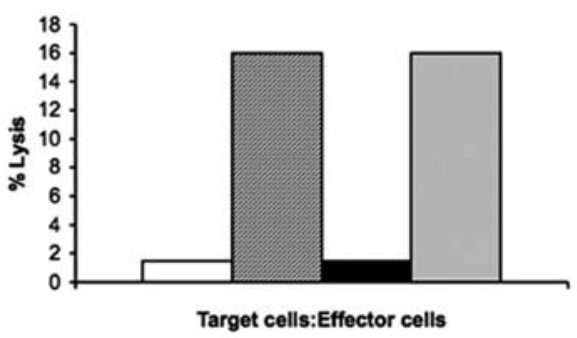

B

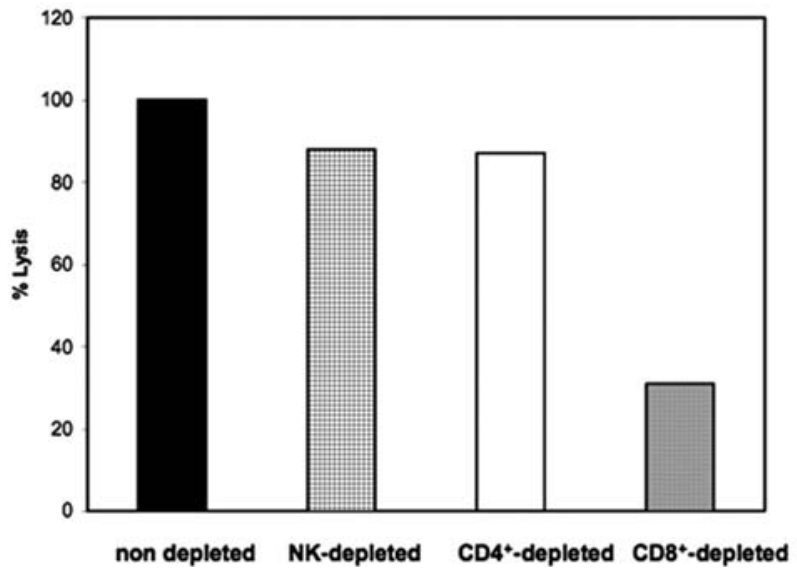

Figure 1. Characterization of tumor-specific cytotoxic $\mathrm{T}$ cell activity after virotherapy. (A) Splenocytes mediated cytotoxic activity against neuroblastoma cells. Splenocytes from neuroblastoma-cured mice and control mice were prepared as described in Materials and methods. Cytotoxic activity of effector cells prepared from spleens was measured against either Neuro- $2 \mathrm{a}^{\mathrm{CD} 155}$ cells or Neuro-2a cells. The target to effector ratio was 1:50. Results from 3 mice in each group are expressed as mean. Standard deviation of the mean was 0.8 and $0.4 \%$ or less in cytotoxic test using splenocytes from cured or naïve mice, respectively. (B) Cytotoxic response of different cell subset-depleted population. Splenocytes purified from neuroblastomacured mice were depleted of different cell populations and then tested for cytotoxicity against Neuro- $2 \mathrm{a}^{\mathrm{CD} 155}$ cells as described in Material and methods. The cytotoxic effect of each-depleted cell population is expressed as percentage of the specfic cytotoxic effect of non-depleted splenocytes. Results from 3 mice in each group are expressed as mean. Standard deviation of the mean was $3 \%$ or less in all cases.

(Fig. 1B). These data indicate that cytotoxic $\mathrm{CD}^{+} \mathrm{T}$ cells are the principal mediators of antineuroblastoma immunity elicited by $\mathrm{A}_{133}$ Gmono-crePV virotherapy.

Antitumor effect of adoptively transferred splenocytes from cured mice by $A_{133}$ Gmono-crePV virotherapy. To confirm our conclusion about that lysis of neuroblastoma with $\mathrm{A}_{133}$ Gmono-cre $\mathrm{PV}$-induced antitumor immunity in cured A/J mice (Fig. 2A, stage III), we adoptively transferred the splenocytes harvested from the cured mice cured into mice that had developed subcutaneous Neuro- $2 \mathrm{a}^{\mathrm{CD} 155}$ tumor (Fig. 2A, stage V). Splenocytes from naïve mice served as a negative control. Splenocytes from cured or naïve mice were adoptively transferred by tail vein injection $\left(2 \times 10^{7}\right.$ splenocytes in $100 \mu 1$ of PBS) to neuroblastoma-implanted mice after which tumor sizes were measured and tumor volumes 


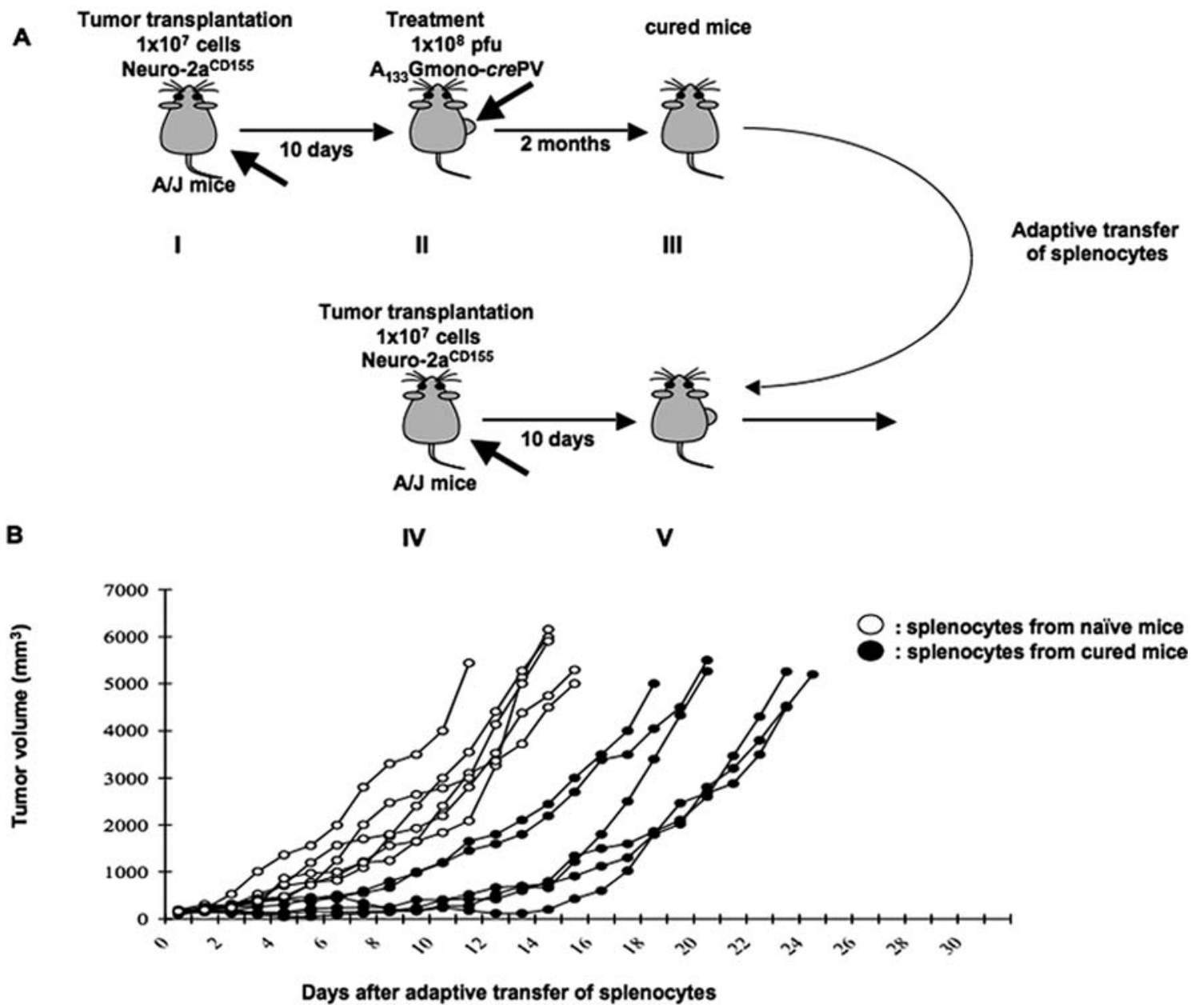

Figure 2. Antitumor effect of adaptively transferred splenocytes. (A) Schematic presentation of $\mathrm{A}_{133} \mathrm{Gmono}-$ crePV therapy on Neuro- $2 \mathrm{a}^{\mathrm{CD} 155}$ tumors in $\mathrm{A} / \mathrm{J}$ mice against poliovirus. Stage I, Neuro-2a $\mathrm{a}^{\mathrm{CD} 155}$ cells were transplanted subcutaneously in A/J mice. Stage II, intratumoral treatment of the subcutaneous tumor with $\mathrm{A}_{133}$ Gmono-crePV (1 $10^{8} \mathrm{pfu}$ ) or PBS. Stage III, mice that survived without signs of tumors for 2 months were sacrificed and splenocytes were purified. Stage IV, prior to adoptive transfer of splenocytes, $1 \times 10^{7}$ cells Neuro-2a ${ }^{\mathrm{CD} 155}$ cells were transplanted subcutaneously in naïve $\mathrm{A} / \mathrm{J}$ mice. Stage $\mathrm{V}$, when the subcutaneous tumor volumes were $\sim 170 \mathrm{~mm}^{3}, 2 \times 10^{7}$ splenocytes in $100 \mu 1$ of PBS were adaptively transferred to the mice (n=6 mice per group) by tail vein injection. (B) Tumor growth of established neuroblastoma implants in A/J mice. Tumor size was measured once a week and tumor volume was determined as described in Materials and methods.

calculated every day. As expected, all the control mice experienced progressive tumor growth and were sacrificed within 21 days (Fig. 2B). In contrast, adoptive transfer of splenocytes from $\mathrm{A}_{133}$ Gmono-crePV-treated mice produced a significant inhibition of tumor growth by comparison with the negative control (average tumor volume: 583 vs. $2183 \mathrm{~mm}^{3}, \mathrm{p}<0.01$ at day 10 post splenocytes transfer). This result confirms that oncolytic therapy for neuroblastoma with attenuated poliovirus induces a tumor-specific immune response.

Induction of antitumor immune response by lysates of $P V$ infected neuroblastoma cells. Tumor destruction by an oncolytic virus can release a wide range of tumor-specific antigens that will be taken up by infiltrating antigen-presenting cells for cross-presentation to $\mathrm{T}$ cells for priming of antigenspecific immune response (25). Based on this premise, we reasoned that immunization with an in vitro $\mathrm{PV}$-infected neuroblastoma cell lysate should be able to prime an effective immune response against tumor cells and subsequently hinder neuroblastoma growth (see Materials and methods and Fig. 3A).
Examination of dead mice showed that i.v. injection of Neuro-2a cells gave rise to multiple liver and perirenal tumors (Fig. 3B). Examination of an antitumor response to immunization with different lysates or PBS was carried out according to the protocol delineated in Fig 3A. Analysis of KaplanMeier curves using the log-rank test showed no difference in the survival kinetics among mice immunized with i) PBS, iii) non-infected Neuro-2 $\mathrm{a}^{\mathrm{CD} 155}$ lysate or iv) a mixture of noninfected Neuro- $2 \mathrm{a}^{\mathrm{CD} 155}$ lysate and poliovirus ( $\mathrm{p}>0.05$, Fig. $3 \mathrm{C}$ ). All mice from these groups died before 90 days of tumor challenge. In contrast, $70 \%$ of mice immunized with ii) PVinfected Neuro-2 $\mathrm{a}^{\mathrm{CD} 155}$ lysate, survived beyond 100 days after tumor challenge (Fig. 3C). Furthermore, statistical analyses showed that immunization with PV-infected Neuro-2a $\mathrm{a}^{\mathrm{CD} 155}$ lysate was superior to any of the immunization with other lysates or PBS ( $\mathrm{p}<0.01$, Fig. $3 \mathrm{C}$ ). We ruled out the possibility that protection effect seen in mice immunized with $\mathrm{PV}$-infected Neuro- $2 \mathrm{a}^{\mathrm{CD} 155}$ lysate is due to a cytolytic effect by an ongoing poliovirus infection after lysate injection. Our assertion is based in the following facts: a) no poliovirus were isolated from the lung, liver, spleen, brain and spinal cord of mice at 
A
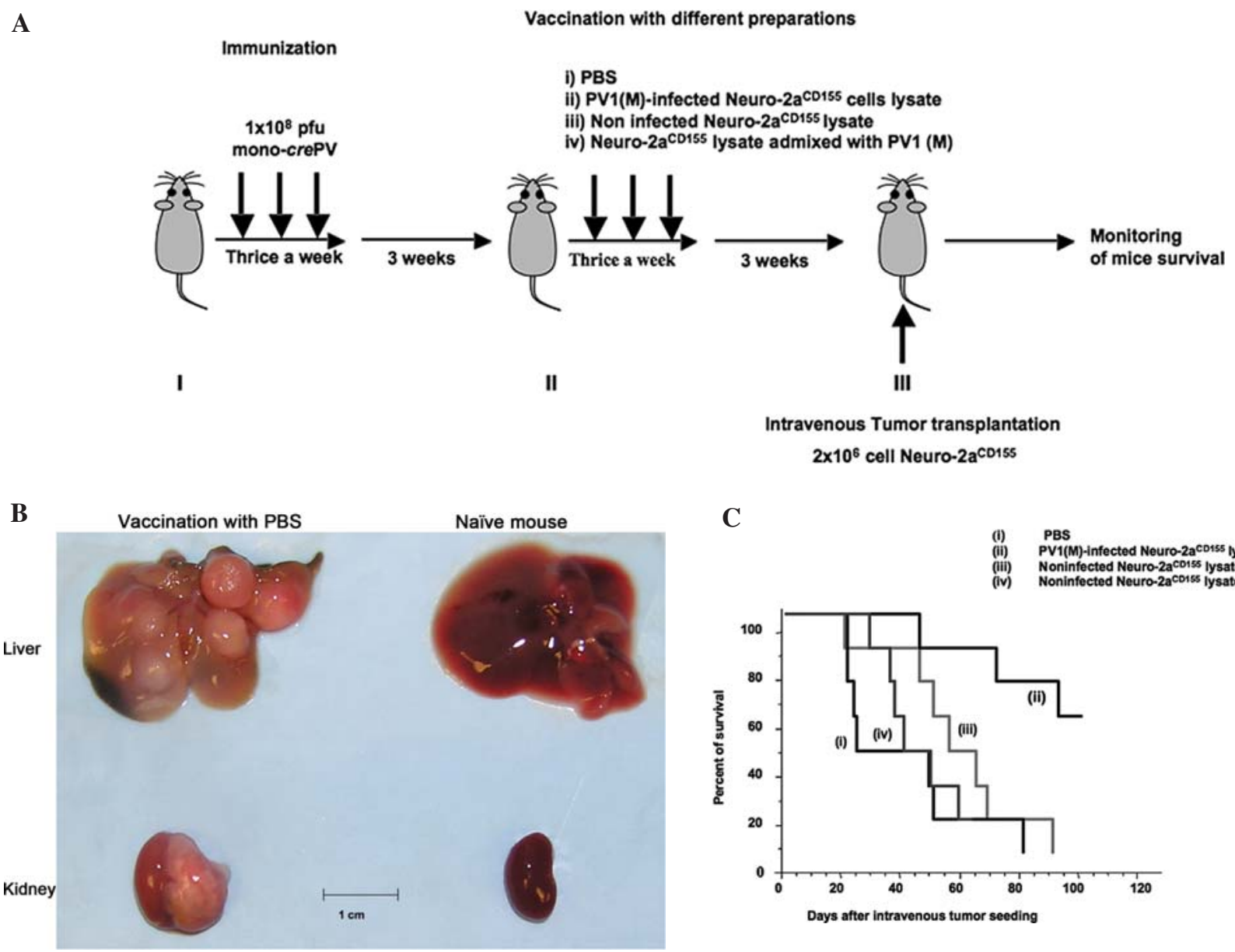

Figure 3. (A) Monitoring of mouse survival. Antitumor effect of vaccination with PV-infected Neuro- $2 \mathrm{a}^{\mathrm{CD} 155}$ lysate. Schematic presentation of vaccination with non-infected and PV-infected Neuro-2 $\mathrm{a}^{\mathrm{CD} 155}$ lysates Stage I, CD155 tgA/J mice were immunized intraperitoneally with live mono-crePV (1x10 ${ }^{8}$ pfu) thrice with an interval one week. Stage II, 21 days after the last immunization, polio-immunized $C D 155$ tgA/J mice were vaccinated intraperitoneally with different cell lysates as described in Materials and methods with an interval one week. Stage III, 21 days after the last vaccination, $2 x 10^{6}$ cells of Neuro$2 \mathrm{a}^{\mathrm{CD} 155}$ cells were transplanted intravenously into the animals. (B) Growth of intravenously implanted tumors. Liver and kidney extracted from the mouse that was vaccinated with PBS and received intravenous injection of Neuro- $2 \mathrm{a}^{\mathrm{CD} 155}$ cells (left). Naïve mouse was used as a control (right). (C) Percentage of survival mice after intravenous Neuro- $2 \mathrm{a}^{\mathrm{CD} 155}$ injection. Mice were vaccinated with different lysates prior i.v. challenge with Neuro- $2 \mathrm{a}^{\mathrm{CD} 155}$ as described in Materials and methods. Animals were observed every day and survival was plotted using a Kaplan-Meier survival curve.

the time of tumor challenge, i.e., 21 days after vaccination with homogenates prepared from PV1(M)-infected Neuro$2 \mathrm{a}^{\mathrm{CD} 155}$ cells or non-infected Neuro- $2 \mathrm{a}^{\mathrm{CD} 155}$ admixed with poliovirus, b) no protection was induced by non-infected Neuro- $2 \mathrm{a}^{\mathrm{CD} 155}$ admixed with poliovirus, and c) all mice have been previously immunized against poliovirus. Altogether, our results suggest that an in vitro infection of neuroblastoma cells with PV turn these cells into a potent tumor immunogen.

\section{Discussion}

In this study, we show that intratumoral inoculation of attenuated poliovirus strain into Neuro- $2 \mathrm{a}^{\mathrm{CD} 155}$ tumors in immunocompetent $C D 155 \mathrm{tg} \mathrm{A} / \mathrm{J}$ mice induces a systemic $\mathrm{CD}^{+} \mathrm{T}$ cell-mediated immunity against neuroblastoma. Previous investigations in mice and humans have also shown that treatment with oncolytic viruses can result in the enhancement of an antitumor immune response (11-17). Such an immune response generated by oncolytic viruses has several advantages over cancer vaccines based on identified tumor antigen. Oncolytic virotherapy can provoke the release of a potentially large repertoire of tumor antigens. Furthermore, a proinflammatory response might ensue after the intratumoral viral replication. This inflammatory response can induce the recruitment, activation and loading of antigen-presenting cells with tumor antigens, providing an opportunity for efficient presentation of these antigens to $\mathrm{T}$ cells $(11,26,27)$. Moreover, the proinflammatory signals triggered by virotherapy may help to breach the tumor-related immunosuppressive barrier and facilitate the infiltration of tumorspecific immune cells to the tumor site.

Interestingly, the oncolytic virotherapy described here generated a similar cytotoxic response against both Neuro-2a and Neuro- $2 \mathrm{a}^{\mathrm{CD} 155}$. This result indicates that ectopic expression of human CD155, the cellular receptor for PV, in murine Neuro-2a cells is not a target for T cell-mediated cytotoxicity in our model. In humans, on the other hand, CD155 binds CD96 and CD226 $(28,29)$. It has been shown that CD155/ CD96/226 interaction is of importance in the NK-based killing activity or in CD8 $\mathrm{T}$ cell-mediated tumor rejection (30,31). Moreover, CD96/CD155-interaction is preserved between man and mouse (32). Although both receptors are 
only moderately conserved in amino acid sequence, the splenocytes-mediated cytotoxicity observed in our study could potential be mediated by the interaction between murine CD96/226 (in NK and T cells) and human CD155 (in Neuro- $\left.2 \mathrm{a}^{\mathrm{CD} 155}\right)$. Our results suggest that the lysis of Neuro$2 \mathrm{a}^{\mathrm{CD} 155}$ is not mediated by CD155/CD96/226 interaction since the cytotoxic activity of neuroblastoma-cured splenocytes against both Neuro-2a and Neuro-2 $\mathrm{a}^{\mathrm{CD} 155}$ was similar.

Significant tumor growth suppression was observed in naïve mice engrafted with splenocytes from mouse donors that had been treated for neuroblastoma with $\mathrm{A}_{133}$ GmonocrePV-virotherapy. This result confirms that in vivo treatment of neuroblastoma by oncolytic poliovirus induces the generation of tumor-sensitized $\mathrm{T}$ lymphocytes in host mice. Our results also show a difference in tumor growth inhibition among mice engrafted with neuroblastoma-reactive splenocytes. A possible explanation is that the variation observed reflects the incidence of tumor-reactive $\mathrm{T}$ cells in the splenocytes populations adoptively transferred to the naive mice. Moreover, the levels of the neuroblastomareactive $\mathrm{T}$ cells present in the spleens of donors might be determined by the extent of tumor lysis induced by virotherapy which in turn influence upon the magnitude of the elicited antitumor immune responses.

Tumor-associated antigens are not well characterized for the majority of human tumors. Therefore, cancer vaccines derived from whole tumor are an attractive approach to induce a broad range of antitumor immunity. However, immunization using intact tumor cells has shown a poor treatment outcome for cancer (33). It has long been assumed that most therapeutic agents kill tumor cells through apoptosis. Notably, apoptosis has been considered to be a nonimmunogenic or even a tolerogenic cell death mechanism as opposed to necrosis (an immunogenic cell death). However, depending on the cell death inducer, tumor cells can become highly immunogenic and induce a potent antitumor response in vivo (34). Furthermore, there is now persuasive evidence that cell death can trigger an immune response only if the dying cells emit 'eat-me', 'danger' and 'killing' signals that mediate their efficient phagocytosis by dendritic cells (DC's) and the maturation of DCs (20,35-38). DCs are the most important professional antigen-presenting cells and play a central role in initiating innate and adaptive immune response against tumor associate antigens. Antigen presentation by immature DCs (iDCs), associated with a lack of costimulation, induces tolerance. A number of molecules released from dying cells have been identified to elicit immune signaling during immunogenic cell death. These include, among others, high mobility group box 1 (HMGB1, also known as amphoterin), purine metabolites (uric acid), calreticulin (CRT), and heat shock proteins (HSP) $(18,39-41)$.

Until now, most of the identified inducers of immunogenic cell death of tumors cells are chemotherapeutics (42). The potent antitumor response elicited by virotherapy, observed by us and other investigators $(10,43)$, clearly suggests that viruses are in vivo inducers of immunogenic death of tumor cells. Moreover, our finding that inoculation of PV-infected neuroblastoma lysate protects against live tumor challenge indicates that poliovirus is also an in vitro inducer of immunogenic death. Interestingly, necrosis by freeze thawing is also considered to induce an immunological cell death (42). However, we observed that immunization with lysate from freeze-thawed non-infected neuroblastoma, as opposed to the $\mathrm{PV}$-infected lysate, did not protect against live tumor challenge. This result underscores the capacity of poliovirus to trigger the release of danger signals from tumor cells, which in turn will induce an antitumor response. Significantly, cells infected with encephalomyocarditis virus, a picornavirus just like PV, have been shown to be effective at presenting non-viral antigens for cross-priming of DCs in vivo (44). Viral lysates (called oncolysate) have been used in the past to vaccinate human against cancer (45). Those few trials have shown some degrees of success, but results have been ambiguous $(39,46,47)$. Remarkably, treatment with viral oncolysates showed better overall survival than radio- and chemotherapy, probably because of the harmful effects that these conventional therapies have on the immune system (48).

In conclusion, we have shown that $\mathrm{A}_{133}$ Gmono-crePV, an oncolytic virus derived from $\mathrm{PV}$, can induce an effective antitumor immune response in addition to its tumor cell killing mechanism. Furthermore, the vaccination with a polio-infected neuroblastoma lysate is also able to induce a potent antitumor immunity.

With current methods, it is likely that virotherapy using attenuated poliovirus will be capable of eradicating neuroblastoma when used in combination with other therapies. Moreover, immunotherapy with PV oncolysate alone or in combination with virotherapy can be effective in controlling minimal residual and metastatic diseases states, thereby preventing recurrence or prolonging the time of recurrence in patient suffering from neuroblastoma.

We consider it possible that PV-based cancer therapy may have broad application beyond the treatment and cure of neuroblastoma. It should be mentioned that very different PV derivative, a chimera between PV and human rhinovirus, called PV(RIPO), offers hope as oncolytic virus against tumors affecting the central nervous system $(7-9,49)$. PV(RIPO), however, does not lyse human or mouse neuroblastoma cells efficently, precluding this derivate from the studies described in this study.

Finally, the antitumor response induced by polio oncolysate remains largely uncharacterized. Therefore, a detailed knowledge of the immune response and therapeutic protection elicited by polio-infected tumor lysates is needed.

\section{Acknowledgments}

Supported by NIAID Grants AI039385-07 and AI15122-34 to E.W. Supported by Stony Brook University Center, Catacosinos Award in Cancer Research to E.W and J.C. H.T was the recipient of a scholarship from Pediatric Oncology Research Foundation.

\section{References}

1. Brodeur GM and Maris JM: Neuroblastoma. In: Principles and Practice of Pediatric Oncology. Pizzo PA and Poplack DG (eds). Lippincott, Williams and Wilkins, Philadelphia, pp933-970, 2006.

2. Matthay KK, Villablanca JG, Seeger RC, et al: Treatment of high-risk neuroblastoma with intensive chemotherapy, radiotherapy, autologous bone marrow transplantation, and 13-cisretinoic acid. N Engl J Med 341: 1165-1173, 1999. 
3. Matthay KK, Reynolds CP, Seeger RC, et al: Long-term results for children with high-risk neuroblastoma treated on a randomized trial of myeloablative therapy followed by 13-cis-retinoic acid: a Children's Oncology Group study. J Clin Oncol 27: 10071013,2009

4. Kirn D, Martuza RL and Zwiebel J: Replication-selective virotherapy for cancer: Biological principles, risk management and future directions. Nat Med 7: 781-787, 2001.

5. Parato KA, Senger D, Forsyth PA and Bell JC: Recent progress in the battle between oncolytic viruses and tumours. Nat Rev Cancer 5: 965-976, 2005.

6. Vähä-Koskela MJ, Heikkilä JE and Hinkkanen AE: Oncolytic viruses in cancer therapy. Cancer Lett 254: 178-216, 2007.

7. Gromeier M, Lachmann S, Rosenfeld MR, Gutin PH and Wimmer E: Intergeneric poliovirus recombinants for the treatment of malignant glioma. Proc Natl Acad Sci USA 97: 6803-6808, 2000 .

8. Ochiai H, Campbell SA, Archer GE, et al: Targeted therapy for glioblastoma multiforme neoplastic meningitis with intrathecal delivery of an oncolytic recombinant poliovirus. Clin Cancer Res 12: 1349-1354, 2006.

9. Ochiai H, Moore SA, Archer GE, et al: Treatment of intracerebral neoplasia and neoplastic meningitis with regional delivery of oncolytic recombinant poliovirus. Clin Cancer Res 10: 4831-4838, 2004.

10. Toyoda H, Yin J, Mueller S, Wimmer E and Cello J: Oncolytic treatment and cure of neuroblastoma by a novel attenuated poliovirus in a novel poliovirus-susceptible animal model. Cancer Res 67: 2857-2864, 2007.

11. Diaz RM, Galivo F, Kottke T, Wongthida P, et al: Oncolytic immunovirotherapy for melanoma using vesicular stomatitis virus. Cancer Res 67: 2840-2848, 2007.

12. Greiner S, Humrich JY, Thuman P, Sauter B, Schuler G and Jenne L: The highly attenuated vaccinia virus strain modified virus Ankara induces apoptosis in melanoma cells and allows bystander dendritic cells to generate a potent anti-tumoral immunity. Clin Exp Immunol 146: 344-353, 2006.

13. Moehler MH, Zeidler M, Wilsberg V, et al: Parvovirus H-1induced tumor cell death enhances human immune response in vitro via increased phagocytosis, maturation, and cross-presentation by dendritic cells. Hum Gene Ther 16: 996-1005, 2005.

14. Li H, Dutuor $\mathrm{A}, \mathrm{Fu} \mathrm{X}$ and Zhang $\mathrm{X}$ : Induction of strong antitumor immunity by an HSV-2-based oncolytic virus in a murine mammary tumor model. J Gene Med 9: 161-169, 2007.

15. Li H, Dutuor A, Tao L, Fu X and Zhang X: Virotherapy with a type 2 herpes simplex virus derived oncolytic virus induces potent antitumor immunity against neuroblastoma. Clin Cancer Res 13: 316-332, 2007.

16. Qiao J, Kottke T, Willmon C, F. Galivo, et al: Purging metastases in lymphoid organs using a combination of antigen non-specific adoptive $\mathrm{T}$ cell therapy, oncolytic virotherapy and immunotherapy. Nat Med 14: 37-44, 2008.

17. Toda M, Rabkin SD, Kojima $H$ and Martuza RL: Herpes simplex virus as an in situ cancer vaccine for the induction of specific anti-tumor immunity. Hum Gene Ther 10: 385-393, 1999.

18. Obeid M, Tesniere A, Ghiringhelli F, et al: Calreticulin exposure dictates the immunogenicity of cancer cell death. Nat Med 13: 54-61, 2007

19. Obeid M, Panaretakis T, Joza N, et al: Calreticulin exposure is required for the immunogenicity of gamma-irradiation and UVC light induced apoptosis. Cell Death Differ 14: 1848-1850, 2007.

20. Blachère NE, Darnell RB and Albert ML: Apoptotic cells deliver processed antigen to dendritic cells for cross-presentation PLoS Biol 3: 1070-1078, 2005.

21. Cello J, Paul AV and Wimmer E: Chemical synthesis of poliovirus cDNA: generation of infectious virus in the absence of natural template. Science 297: 1016-1018, 2002.

22. Mueller S and Wimmer E: Recruitment of nectin-3 to cell-cell junctions through trans-heterophilic interaction with CD155, a vitronectin and poliovirus receptor that localizes to alpha(v) beta3 integrin-containing membrane microdomains. J Biol Chem 278: 31251-31260, 2003.

23. Decker T and Lohmann-Matthes ML: A quick and simple method for the quantitation of lactate dehydrogenase release in measurements of cellular cytotoxicity and tumor necrosis factor (TNF) activity. J Immunol Methods 115: 61-69, 1988.

24. Koike S, Taya C, Kurata T, et al: Transgenic mice susceptible to poliovirus. Proc Natl Acad Sci USA 88: 951-955, 1991.

25. O'Shea CC: Viruses-seeking and destroying the tumor program. Oncogene 24: 7640-7655, 2005.
26. Matzinger P: An innate sense of danger. Semin Immunol 10: 399-415, 1998.

27. Steinman RM, Turley S, Mellman I and Inaba K: The induction of tolerance by dendritic cells that have captured apoptotic cells. J Exp Med 191: 411-416, 2000.

28. Fuchs A, Cella M, Giurisato E, Shaw AS and Colonna M: Cutting edge: CD96 (tactile) promotes NK cell-target cell adhesion by interacting with poliovirus receptor (CD155). J Immunol 172: 3994-3998, 2004.

29. Pende D, Bottino C, Castriconi R, et al: PVR (CD155) and Nectin-2 (CD112) as ligands of the human DNAM-1 (CD226) activating receptor: involvement in tumor cell lysis. Mol Immunol 42: 463-469, 2005

30. Bottino C, Castriconi R, Pende D, et al: Identification of PVR (CD155) and Nectin-2 (CD112) as cell surface ligands for the human DNAM-1 (CD226) activating molecule. J Exp Med 198: 557-567, 2003.

31. Tahara-Hanaoka S, Shibuya K, Kai H, et al: Tumor rejection by the poliovirus receptor family ligands of the DNAM-1 (CD226) receptor. Blood 107: 1491-1496, 2006

32. Seth S, Maier MK, Qiu Q, et al: The murine pan T cell marker CD96 is an adhesion receptor for CD155 and nectin-1. Biochem Biophys Res Commun 364: 959-965, 2007.

33. Rosenberg SA, Yang JC and Restifo NP: Cancer immunotherapy: moving beyond current vaccines. Nat Med 10: 909-915, 2004.

34. Zitvogel L, Tesniere A and Kroemer G: Cancer despite immunosurveillance: immunoselection and immunosubversion. Nat Rev Immunol 6: 715-727, 2006.

35. Casares N, Pequignot MO, Tesniere A, et al: Caspase dependent immunogenicity of doxorubicininduced tumor cell death. J Exp Med 202: 1691-1701, 2005

36. Kepp O, Senovilla L, Galluzzi L, et al: Viral subversion of immunogenic cell death. Cell Cycle 8: 860-869, 2009.

37. Melcher A, Todryk S, Hardwick N, Ford M, Jacobson M and Vile RG: Tumor immunogenicity is determined by the mechanism of cell death via induction of heat shock protein expression. Nat Med 4: 581-587, 1998.

38. Sauter B, Albert ML, Francisco L, Larsson M, Somersan S and Bhardwaj N: Consequences of cell death: exposure to necrotic tumor cells, but not primary tissue cells or apoptotic cells, induces the maturation of immunostimulatory dendritic cells. J Exp Med 191: 423-434, 2000.

39. Freedman RS, Edwards CL, Bowen JM, Lotzova E, Katz R, Lewis E, Atkinson N and Carsetti R: Viral oncolysates in patients with advanced ovarian cancer. Gynecol Oncol 29: 337-347, 1988.

40. Shi Y, Evans JE and Rock KL: Molecular identification of a danger signal that alerts the immune system to dying cells. Nature 425: 516-521, 2003.

41. Udono $\mathrm{H}$ and Srivastava PK: Comparison of tumor-specific immunogenicities of stress induced proteins gp96, hsp90, and hsp70. J Immunol 152: 5398-5403. 1994.

42. Ullrich E, Bonmort M, Mignot G, Kroemer G and Zitvogel L: Tumor stress, cell death and the ensuing immune response. Cell Death Differ 15: 21-28, 2008.

43. Sinkovics J and Horvath J: New developments in the virus therapy of cancer: a historical review. Intervirology 36: 193-214, 1993.

44. Schulz O, Diebold SS, Chen M, et al: Toll-like receptor 3 promotes cross-priming to virus infected cells. Nature 433: 887-892, 2005

45. Sinkovics JG and Horvath JC: Evidence accumulating in support of cancer vaccines combined with chemotherapy: a pragmatic review of past and present efforts. Int J Oncol 29: 765-777, 2006.

46. Murray DR, Cassel WA, Torbin AH, Olkowski ZL and Moore ME: Viral oncolysate in the management of malignant melanoma. II. Clinical studies. Cancer 40: 680-686, 1977.

47. Cassel WA and Murray DR: A ten-year follow-up on stage II malignant melanoma patients treated postsurgically with Newcastle disease virus oncolysate. Med Oncol Tumor Pharmacother 9: 169-171, 1992.

48. White RR, Stanley WE, Johnson JL, Tyler DS and Seigler HF: Long-term survival in 2505 patients with melanoma with regional lymph node metastasis. Ann Surg 235: 879-887, 2002.

49. Goetz $\mathrm{C}$ and Gromeier M: Preparing an oncolytic poliovirus recombinant for clinical application against glioblastoma multiforme. Cytokine Growth Factor Rev 21: 197-203, 2010. 